\title{
INSTITUTE OF EAST ASIAN STUDIES
}

UNIVERSITY OF CNIFORUIA, BERKELEY

The Institute of East Asian Studies was established at the University of California, Berkeley, in the fall of 1978 to promote research and teaching on the cultures and societies of China, Japan, and Korea. It amalgamates the following research and instructional centers and programs: Center for Chinese Studies, Center for Japanese Studies, Center for Korean Studies, Group in Asian Studies, and the East Asia National Resource Center.

Institute of East Asian Studies

Director: Robert A. Scalapino

Assistant Director: Ernest J. Notar

Executive Committee

Robert N. Bellah

Van C. Gessel

Chaimers Johnson

Joyce K. Kallgren

William H. McCullough

Ernest J. Notar

Robert R. Reed

Michael C. Rogers

Robert A. Scalapino

Center for Chinese Studies

Chairman: Joyce K. Kallgren

Center for Japanese Studies

Chairman: Willian H. McCullough

Center for Korean Studies

Chairman: Michael C. Rogers

Group in Asian Studies

Chairman: Robert R. Reed

East Asia National Resource Center

Director: Van C. Gessel 